\title{
Deaggregation of probabilistic ground motions in the Kota Kinabalu and Lahad Datu towns of Sabah, Malaysia
}

\author{
Harith Noor Sheena Herayani ${ }^{1, *}$, Adnan Azlan ${ }^{2}$, and Shoushtari Abdollah Vaez ${ }^{3}$ \\ ${ }^{1}$ Civil Engineering Program, Faculty of Engineering, Universiti Malaysia Sabah, Jalan UMS, 88400 \\ Kota Kinabalu, Sabah, Malaysia \\ ${ }^{2}$ Department of Structure and Materials, Faculty of Civil Engineering, Universiti Teknologi Malaysia, \\ Skudai, 81310, Johor Bahru, Malaysia \\ ${ }^{3}$ Department of Civil Engineering, Islamic Azad University, Khorasgan Branch, University Blvd, \\ Arqavanieh Jey Street, Isfahan, Iran 81595-158
}

\begin{abstract}
Sabah has witnessed an increase in low to moderate seismic activities due to a few active fault lines. According to the historical records ranging between 1900 and 2017, the region already experienced a devastating earthquake with a size $\mathrm{M}_{\mathrm{w}} 5.8$ in Lahad Datu and just last two years with a size $M_{\mathrm{W}} 6.0$ in Ranau. Over the years, more than 400 with size ranging from $\mathrm{M}_{\mathrm{W}} 2.9$ to 6.0 are known to have occurred. There are three tectonic features that affected Sabah namely; subduction zone, strike-slip earthquake and local background seismicity zone. The effects of the earthquakes should be anticipated in order to mitigate the catastrophic failure of structures. Therefore, seismic hazard analysis, such as probabilistic seismic hazard analysis (PSHA) is required. This study deaggregated the PSHA results of $2 \%$ and $10 \%$ probability of exceedance in 50 years. The deaggreagation of selected cities in Sabah such as Kota Kinabalu and Lahad Datu to help understand the relative control of local fault sources in terms of distances and magnitudes. The contribution to hazard indicated that the distance from the earthquake which contributes most to the hazard at each city is mainly controlled by shaking by near seismic area sources.
\end{abstract}

\section{Introduction}

Sabah is one of the Malaysian states bordered internationally with Brunei Darussalam and Kalimantan, Indonesia located on the island of Borneo. Sabah is considered as a relatively stable continental shield region with moderate seismicity $[1,2]$. Sabah is situated in the eastern part of East Malaysia and is bounded by three seas; South China Sea, Sulu Sea and the Celebes Sea. The total land area of Sabah is nearly $72,500 \mathrm{~km}^{2}$. By referring to the 2015 Malaysian Census, the population of Sabah being the third most populous state in Malaysia with a total of $3,543,500$ including non-citizens population at 870,400 . The population is

\footnotetext{
*Corresponding author: sheena@ums.edu.my
} 
particularly concentrated in the coastal areas. Sabah's economy is mainly based on agriculture, forestry, petroleum, tourism and services.

Sabah is prone to earthquake activities if compared to other parts of Malaysia. The region already experienced a devastating earthquake with a magnitude of $\mathrm{M}_{\mathrm{W}} 5.8$ on $26^{\text {th }}$ July 1976 centered in Lahad Datu area. The largest ever recorded with $\mathrm{M}_{\mathrm{W}} 6.0$ on $05^{\text {th }} \mathrm{June}$ 2015 had occurred in Ranau area. A mild earthquake measuring 3.4 occurred near Lahad Datu on $29^{\text {th }}$ March 2017. Even though the magnitude is small, Sabah has records of more than 400 earthquake events occurred between the years 1900 to 2017 (Figure 1) with size ranging from $\mathrm{M}_{\mathrm{W}} 2.9$ to 6.0 are known to have occurred. The condition of the tectonic setting seems to be very complex, with southeasterly subduction in Northwest Borneo and extension in the southeast in the Celebes Sea and Makassar Strait, with evidence of several geological events found in the references $[3,4,5,6]$.

The seismic activity across the region concerns low-to-moderate earthquakes, as presented earlier in Leyu [7] and recent earthquake databases monitored by Alexander [1, 2]. However, it has been recently recognized that this region, even at rather remote distances, is at significant seismic risk from two main active earthquake sources i.e. Indonesia and Philippines. Recently, a large earthquake measuring 7.3 occurred in the Celebes Sea on $10^{\text {th }}$ Jan 2017 with distance $466 \mathrm{~km}$ from east of Sabah. All signs indicate that the same problem will continue in the future. The highest intensity of these earthquakes reached VIII degrees in MMI scale, causing serious economic loss and social unrest.

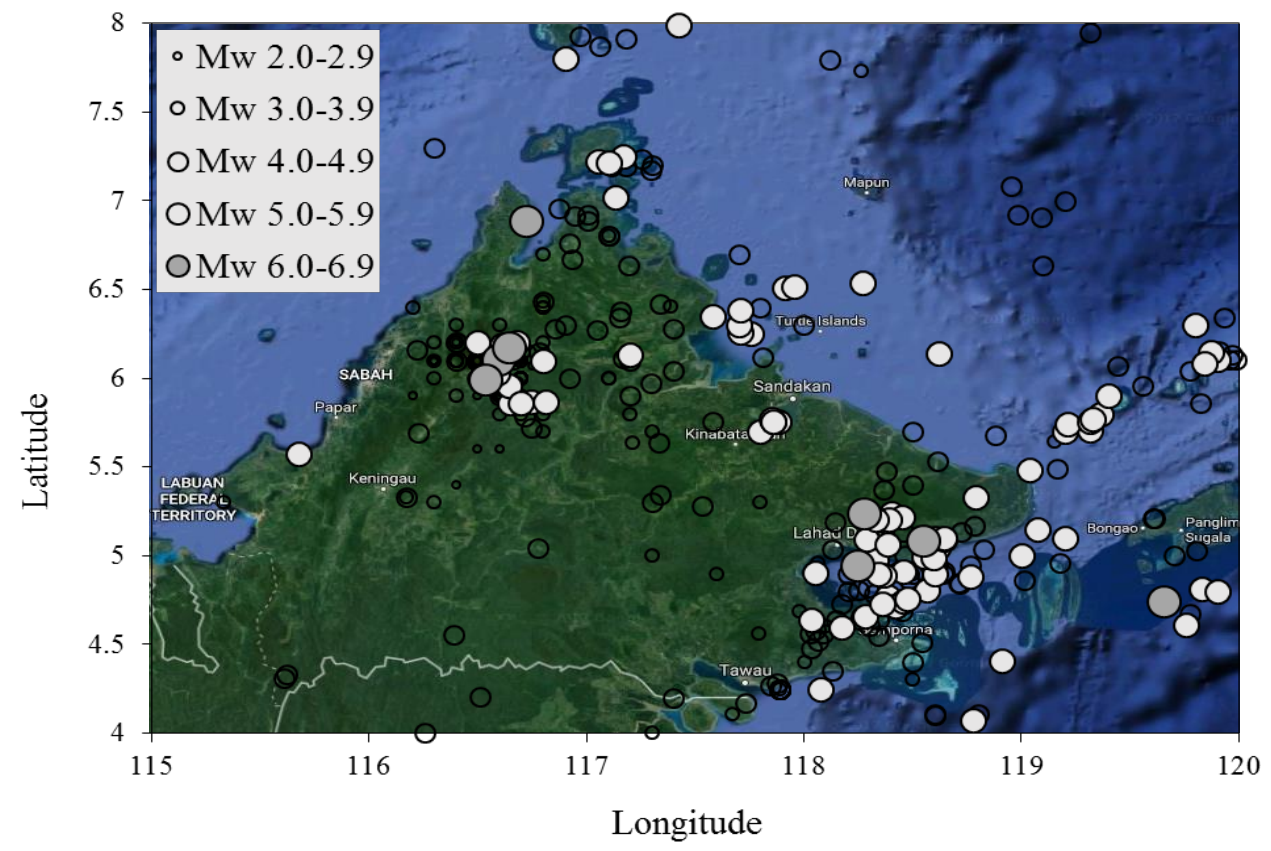

Figure 1. Earthquake events distribution of Sabah province.

Probabilistic Seismic Hazard Analysis (PSHA) approach was adopted to investigate seismic hazard distribution across Sabah. Potential sources of seismic activities in the region were identified, and their earthquake recurrence relationships were developed from instrumental and historical data. The probabilistic seismic hazard assessment (PSHA) is performed in $2 \%$ and $10 \%$ probability of exceedance (PE) in a design time period of 50 years or the corresponding to return period of approximately 500 and 2,500 years, respectively. 
The methodology of this study is based on five main components; (i) data input based on historical earthquake data and the seismotectonic map, (ii) characterization of seismic source with distance up to $600 \mathrm{~km}$, (iii) selection of suitable ground motion prediction equation, (iv) calculation of the seismic hazards and (v) deaggregation analysis. Deaggregation plots can provide useful information on the distance and magnitude of predominant sources, which can be used to generate scenario earthquakes and select corresponding time histories for seismic design.

\subsection{Methodology}

\subsubsection{Earthquake Database}

The geometries of the seismotectonic model were constructed based on earthquake spatial distributions and regional tectonic setting of Sabah. The national earthquake catalog was compiled from historical and instrumental recordings from 1900 to 2017 for a magnitude of 2.0 and above in the vicinity of Sabah region. A large dataset provided by various national and international agencies was collected. The international agencies included the United States Geological Survey/National Earthquake Information Centre (USGS/NEIC), Advanced National Seismic System (ANSS), International Seismological Centre (ISC), National Geophysical Data Centre (NGDC), Harvard Centroid Moment Tensor (CMT), the national agency of the Malaysian Meteorological Department (MMD), and various literature $[7,8]$.

There are two types of earthquake catalogs covered in this study, namely historical and instrumental databases. The historical parts of the catalog are compiled from various literatures, such as Leyu [7] and Alexander [1,2]. The available catalogue was carefully reviewed for uncertainties and completeness. The magnitudes were unified in terms of moment magnitude $\left(\mathrm{M}_{\mathrm{W}}\right)$. The combined catalogues cover areas from $115^{\circ} \mathrm{E}$ to $120^{\circ} \mathrm{E}$ longitude and from $4^{0} \mathrm{~S}$ to $8^{0} \mathrm{~N}$ latitude and include more than 400 earthquake events occurred between the years 1900 to 2017 (Figure 2).

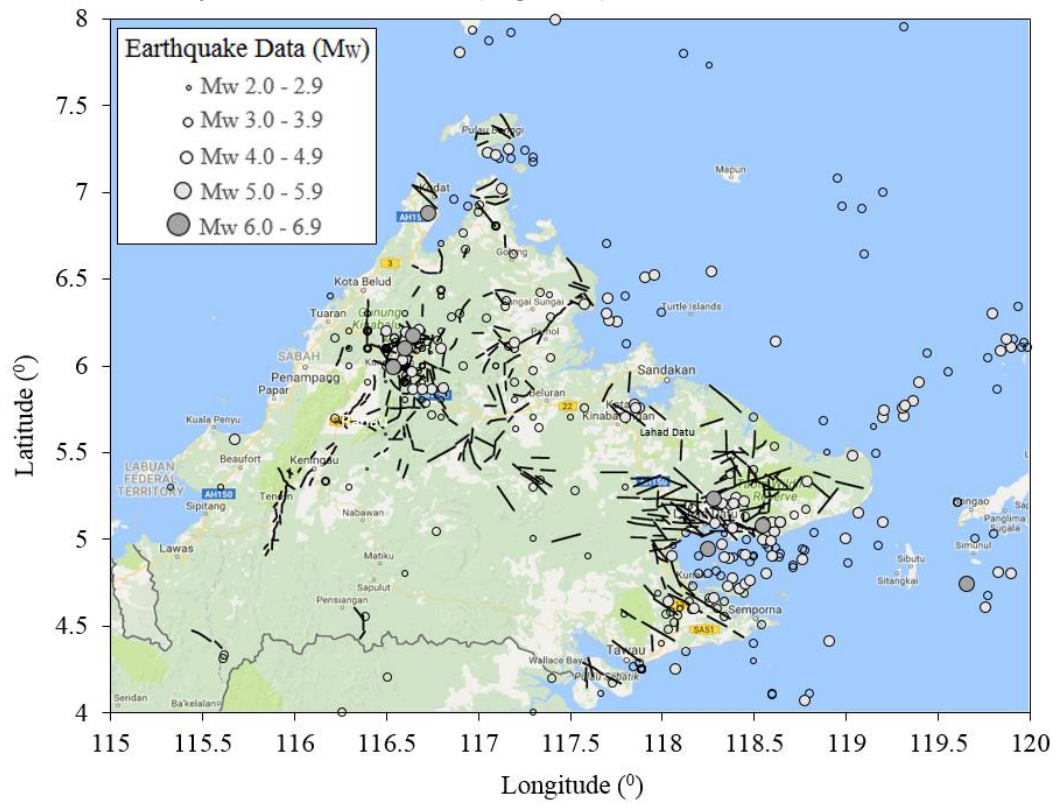

Figure 2. Earthquake events distribution and tectonic map of Sabah province. 


\subsubsection{Seismic Characterization}

In this study, the model of Gardner and Knopoff [9] is being considered in the analysis. The model provides a specific space-time distance as a function of the mainshock magnitude to identify aftershocks. This technique is one of the simplest forms of identifying aftershocks. The historical earthquake data that occurred between 1900 and 2017 is analyzed for completeness. Seismic hazard analysis requires a complete possible history of earthquakes in or near the region of interest. It is necessary to have a comprehensive knowledge of historical recording coverage in order to assess the completeness level of an earthquake catalog.

The historical earthquake data from the earthquake catalogs were then combined with seismotectonic conditions to develop the seismic source model. The seismic source model was characterized by seismic hazard parameters such as a-b values, rates, and maximum magnitudes. The occurrence of earthquakes in a seismic source is assumed as the Poisson distribution. The seismicity parameters are summarized depending on the minimum and maximum magnitude of each zone used in this analysis, which were calculated in the recurrence relationship in Table 1.

Table 1. Recurrence rate parameters for source zones

\begin{tabular}{|c|c|c|c|}
\hline \multirow{2}{*}{ Earthquake Source } & \multicolumn{3}{|c|}{ Recurrence Rate } \\
\cline { 2 - 4 } & $\beta$ & $\lambda$ & $\alpha$ \\
\hline Zone 1 & 0.921 & 0.152 & 1.852 \\
\hline Zone 2 & 0.824 & 0.043 & 1.270 \\
\hline Zone 3 & 0.921 & 0.201 & 2.341 \\
\hline Zone 4 & 0.824 & 0.043 & 1.270 \\
\hline Zone 5 & 1.051 & 0.175 & 2.709 \\
\hline
\end{tabular}

\subsubsection{Ground Motion Prediction Equation (GMPE)}

The prediction of ground motion parameters using probabilistic approach is calculated for the design parameters of earthquake ground motion such as the acceleration at bedrock. The two main uncertainty parameters, ground motion prediction equation, GMPE and maximum magnitude, $\mathrm{M}_{\max }$ incorporated in the hazard estimate used the logic tree to model variable alternatives to avoid being too conservative by over- or underestimating the PGA values. The Next Generation Attenuation (NGA) of the Abrahamson and Silva [10] model was used to analyze ground motions of an earthquake occurring within the active shallow crustal seismogenic zones including Fukushima and Tanaka [11] and Sadigh [12]. In addition, the equation by Zhao [13] was aimed at predicting accelerations for a subduction region (Table 2 ). 
Table 2. Ground motion Prediction Equations (GMPE) adopted in this study

\begin{tabular}{|c|c|}
\hline Reference & Ground motion Prediction Equation (GMPE) \\
\hline Fukushima and Tanaka [11] & $\begin{array}{l}\log (P G A)=0.42 M_{W}-\log \left(R+0.025 \times 10^{0.42 M_{W}}\right. \\
-0.0033 R+1.22\end{array}$ \\
\hline Sadigh [12] & $\begin{array}{l}M_{W} \leq 6.5 ; \\
\ln (P G A)=-0.624+1.0 M_{W}+(-2.1 \ln (R+ \\
\left.\left.\exp \left(1.29649+0.25 M_{W}\right)\right)\right) \\
M_{W}>6.5 ; \\
\ln (P G A)=-1.274+1.1 M_{W}+(-2.1 \ln (R+ \\
\left.\left.\exp \left(-0.48451+0.524 M_{W}\right)\right)\right)\end{array}$ \\
\hline Abrahamson and Silva [10] & $\begin{array}{l}\ln (P G A)=0.804+0.231\left(M_{W}-6.75\right)+(-0.0372 \\
\left.\left(8.5-M_{W}\right)^{2}-0.9679+0.265\left(M_{W}-6.75\right)\right) \ln (R)\end{array}$ \\
\hline Zhao [13] - Megathrust & $\begin{array}{l}\ln (P G A)=1.101 M_{W}+(-0.0564 R)-\ln (R) \\
+0.01412+S_{I}+C_{1}+Q_{I}\left(M_{W}-M^{2}\right)+W_{I}\end{array}$ \\
\hline Zhao [13] - Benioff & $\begin{array}{l}\ln (P G A)=1.101 M_{W}+(-0.0564 R)-\ln (R) \\
+0.01412+S_{S}+S_{S I}\left[\ln \left(R_{\text {hypo }}\right)\right]+C_{1}+P_{S}\left(M_{W}-M\right) \\
+Q_{S}\left(M_{W}-M\right)^{2}+W_{S}\end{array}$ \\
\hline
\end{tabular}

\subsubsection{Seismic Hazard Assessment}

The probability distribution is defined in terms of the annual rate of exceeding the ground motion level at the site under consideration, due to all possible pairs of magnitude and epicentral distance $(\mathrm{M}, \mathrm{R})$ of the earthquake event expected around the site. The seismicity parameters for each source zone were calculated using the method by Gutenberg-Richter (G-R). Table 3 shows the PGA at major towns and villages in Sabah at bedrock level. PGA value at more than $16 \%$ of $\mathrm{g}$ can be seen in Lahad Datu, for 500 years return period, whereas in Kota Kinabalu shows less than $5 \%$ of g. At 2,500 year return period, Lahad Datu gives $27.43 \%$ of $g$ and Kota Kinabalu at $5.6 \%$ of $g$. 
Table 3. PGA values for town areas in Sabah

\begin{tabular}{|c|c|c|c|c|c|}
\hline No & Town Name & Latitude $\left(^{0}\right)$ & Longitude $\left(^{0}\right)$ & $\begin{array}{c}\text { PGA (10\% PE } \\
@ 500-\mathrm{yr}) \% \mathrm{~g}\end{array}$ & $\begin{array}{c}\text { PGA (2\% PE @ } \\
2500-\mathrm{yr}) \% \mathrm{~g}\end{array}$ \\
\hline 1 & Kota Kinabalu & 5.99 & 116.07 & 3.34 & 5.60 \\
\hline 2 & Lahad Datu & 5.02 & 118.33 & 16.36 & 27.43 \\
\hline
\end{tabular}

The probabilistic seismic hazard assessment (PSHA) procedures allow computation of the mean annual rate of exceedance at a particular site based on the aggregate risk from potential earthquakes of many different magnitudes (M) occurring at many different sources to site distances (R) [14]. The rate of exceedance computed in a PSHA, therefore, is not associated with any particular earthquake magnitude or sources to site distance. In some cases, however, it may be useful to estimate the most likely earthquake magnitude and/or the most likely sources to site distance. These quantities may be used, for example, to select existing ground motion records (recorded in earthquakes of similar magnitude at similar source-site distance) for response analysis. Moreover, the results of PSHA can be exploited to determine predominant sources of seismic hazard and can provide deterministic design magnitudes and distances through a process known as seismic hazard deaggregation processes $[15,16]$. The mean annual rate of exceedance as a function of magnitude is shown in equation 1 .

$$
\lambda_{y^{*}}\left(m_{j}\right) \approx P\left[M=m_{j} \sum_{i=1}^{N_{S}} \sum_{k=1}^{N_{R}} v_{i} P\left[Y>y^{*} \mid m_{j}, r_{k}\right] P\left[R=r_{k}\right]\right.
$$

The mean annual rate of exceedance as a function of source-site distance is shown in equation 2.

$$
\lambda_{y^{*}}\left(r_{k}\right) \approx P\left[R=r_{k}\right] \sum_{i=1}^{N_{S}} \sum_{j=1}^{N_{M}} v_{i} P\left[Y>y^{*} \mid m_{j}, r_{k}\right] P\left[M=m_{j}\right]
$$

Finally, it is possible to compute the mean annual rate of exceedance as functions of both earthquake magnitude and source-site distance is shown in equation 3 .

$$
\lambda_{y^{*}}\left(m_{j}, r_{k}\right) \approx P\left[M=m_{j}\right] P\left[R=r_{k}\right] \sum_{i=1}^{N_{S}} v_{i} P\left[Y>y^{*} \mid m_{j}, r_{k}\right]
$$

Performing the PSHA in order to compute the ground-motion parameters (e.g., PGA) at the specific site with the defined percentage of probability of exceedance in a considered exposure time (e.g., $10 \%$ and $2 \%$ probability of exceedance (PE) in 50 years). Based on the above selections the corresponding total mean annual rate of exceedance $\left(\lambda_{\mathrm{y}}{ }^{*}\right.$ (Total)) due to the summation of the calculated seismic hazard curves of the considered seismic sources can be obtained. Then, using the equation above, the mean annual rate of exceedance corresponding to each pair of $\mathrm{M}$ and $\mathrm{R}$, for the obtained $\mathrm{y}^{*}$ should be calculated for each of the seismic sources.

\section{Results}

In order to have more insight into the probabilistic seismic hazard analysis, an attempt is made to deaggregate these ground motions for the two selected cities (i.e. Kota Kinabalu and Lahad Datu). The latitude and longitude for the downtowns of these cities are used to deaggregate their ground motions in terms of bin pairs of magnitude and distance (M, R). 
Deaggregation was carried out based on a magnitude interval of 0.4 and a distance interval of $25 \mathrm{~km}$. Here we account for both aleatory and epistemic uncertainties in the ground motion selection through PSHA deaggregation. The results of the hazard analysis represent the mean of the log-normal distribution ground motion outputs obtained from computations using the above attenuation relationships on bedrock conditions $(\mathrm{Vs}=1500 \mathrm{~m} / \mathrm{s})$. Figure 3 through Figure 6 reflect the deaggregation results for 5\% damping with respect to $10 \%$ and $2 \%$ probability of exceedance in 50 years, respectively.

The mean distance from the controlling earthquake in the Kota Kinabalu city is ranging between $26-75 \mathrm{~km}$ at both $2 \%$ and $10 \%$ probabilities. Contrarily, the more the control is expected from distant very near and ranges between $0-50 \mathrm{~km}$ for both $2 \%$ and $10 \%$ probabilities. The seismic sources are dominated by the source located at a distance less than $100 \mathrm{~km}$. Therefore, at a given probability level, it is clear that for larger and more distant both cities show the less influence to the cities. The controlling earthquake for $10 \%$ and a $2 \%$ probability at Kota Kinabalu city is dominated by an earthquake located at a mean distance of $50 \mathrm{~km}$ and its mean magnitude equals 5.8. In Lahad Datu, the controlling earthquake for $10 \%$ and $2 \%$ probability is dominated by an earthquake located at a mean distance of $25 \mathrm{~km}$ and its mean magnitude equals 5.8 .

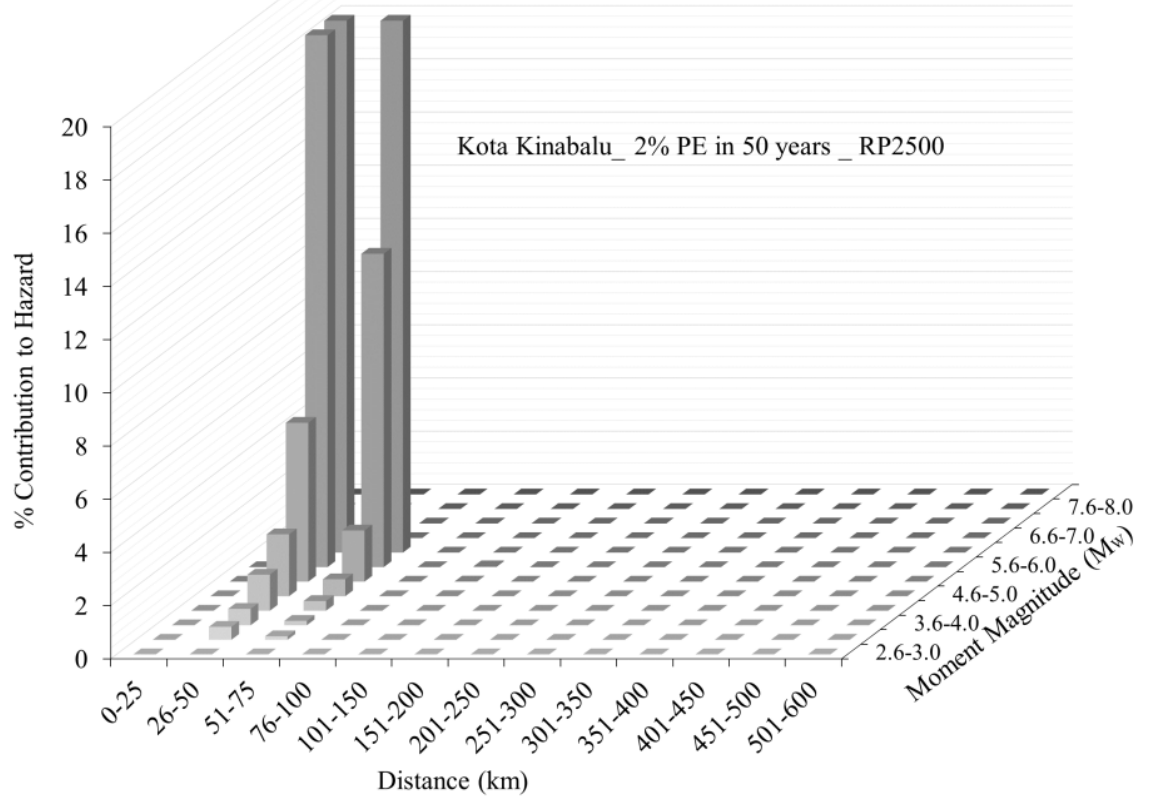

Figure 3. Deaggregation of PSHA results of Kota Kinabalu city for PGA at bedrock at $10 \%$ probability of exceedance. 


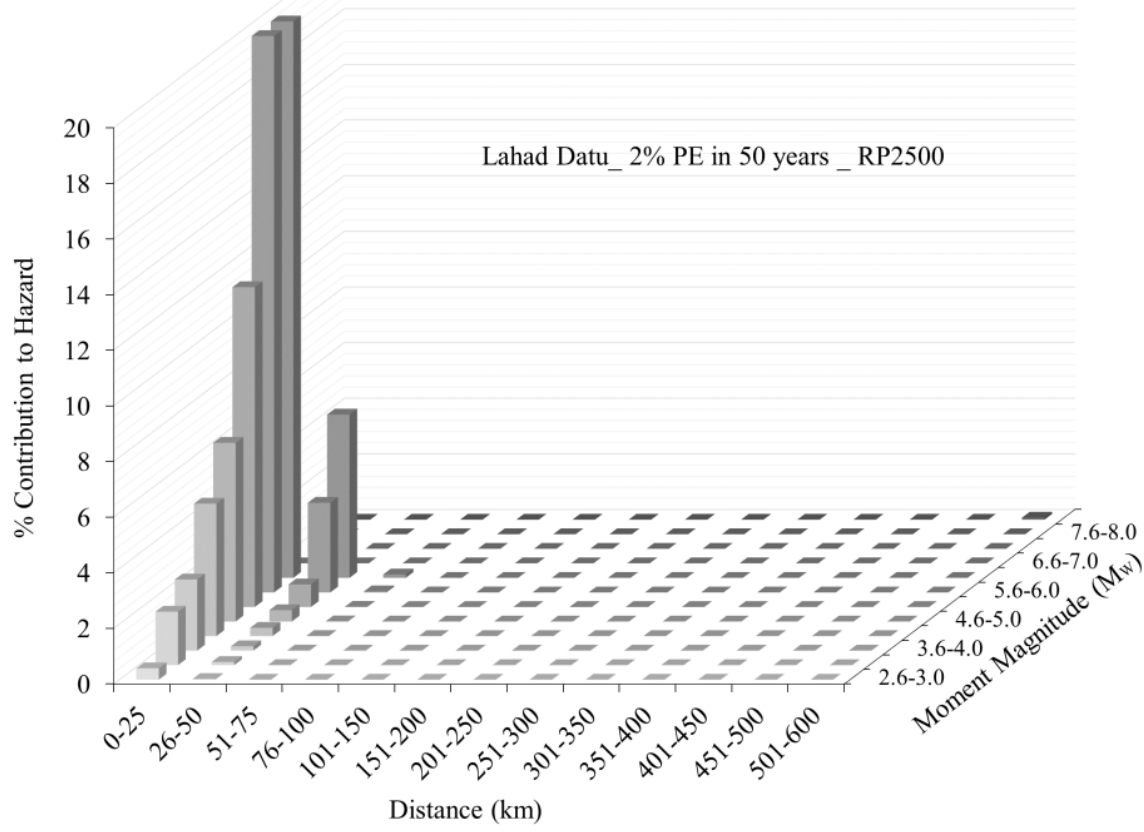

Figure 4. Deaggregation of PSHA results of Lahad Datu city for PGA at bedrock at $10 \%$ probability of exceedance.

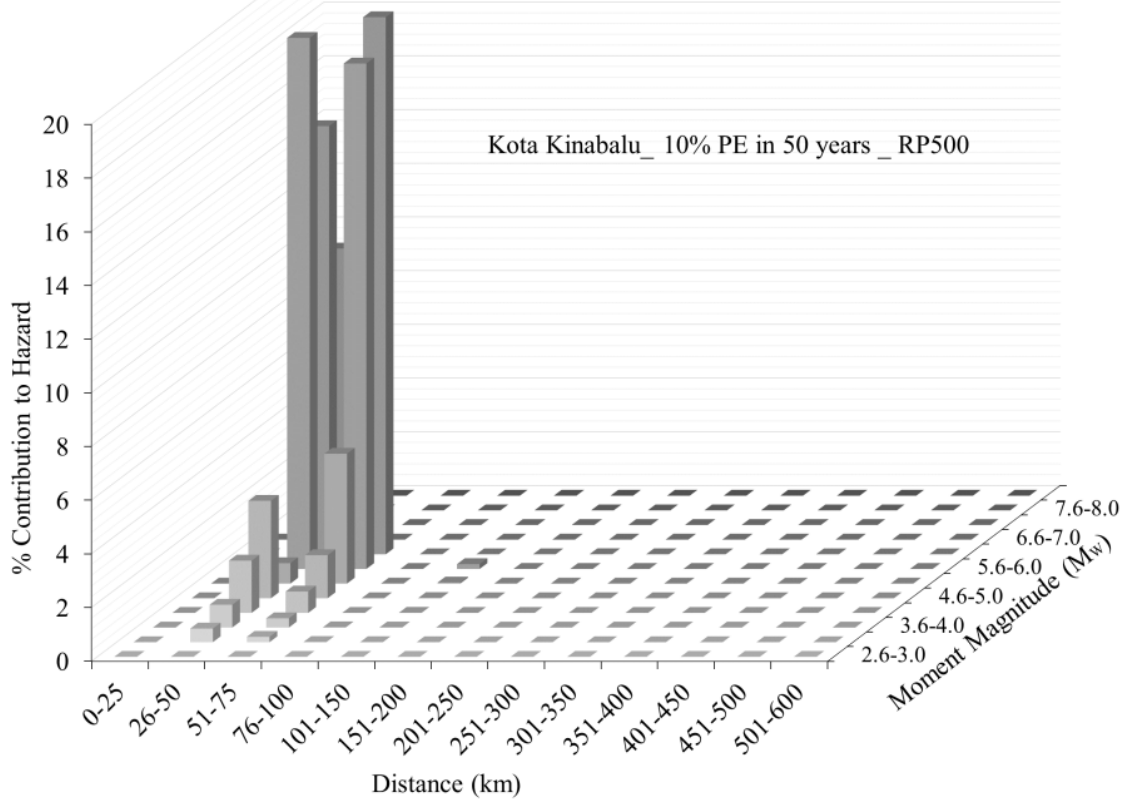

Figure 5. Deaggregation of PSHA results of Kota Kinabalu city for PGA at bedrock at $2 \%$ probability of exceedance. 


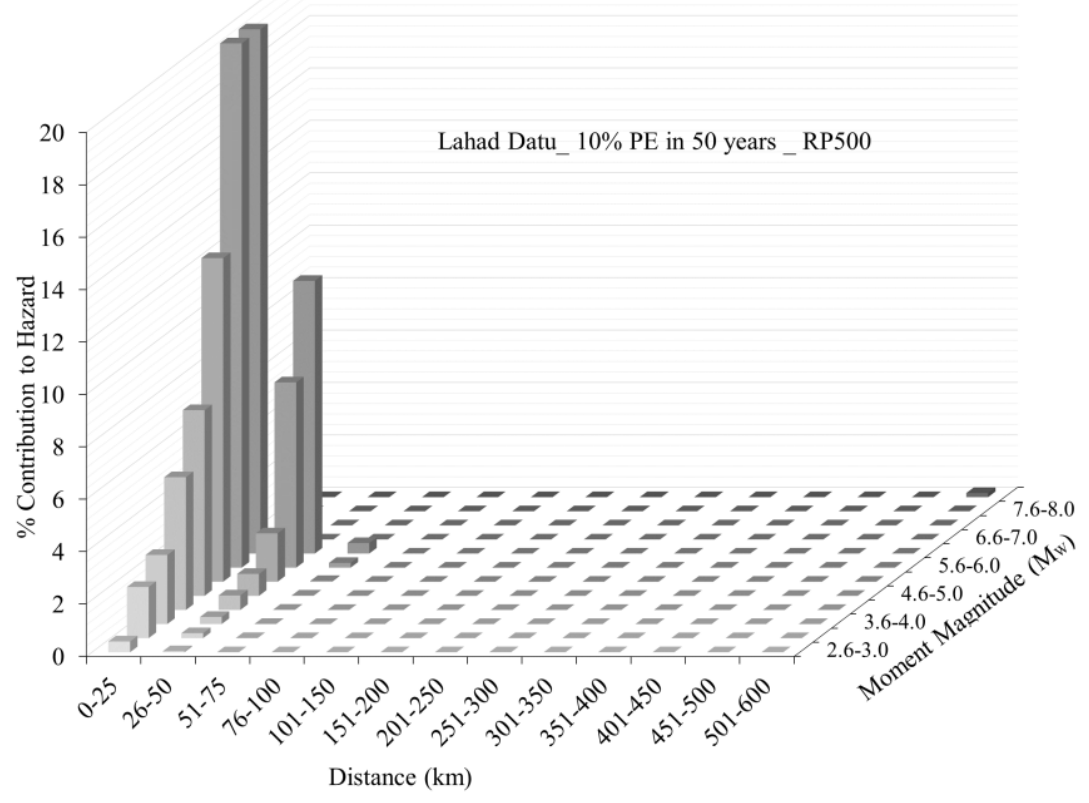

Figure 6. Deaggregation of PSHA results of Lahad Datu city for PGA at bedrock at $2 \%$ probability of exceedance.

\section{Conclusion}

In the present study, the deaggregation of the seismic hazard is performed in order to identify the sources with specific faults that have a major contribution to the hazard of Sabah cities. This study has deaggregated the hazard model of a probability of exceedance for $2 \%$ and $10 \%$ exceedance probability in 50 years. The use of such parameters would better describe the hazard scenarios and allow civil engineers, geologists, seismologists and municipal policy makers to identify either the local and distant sources, or predominant hazardous earthquakes in their design, planning and risk mitigation. The results indicate that very near seismic sources of relative higher magnitudes are the dominating sources of hazard for the selected Sabah cities, where the most probable earthquake is equal to 26-75 $\mathrm{km}$ from Kota Kinabalu city and $0-50 \mathrm{~km}$ to Lahad Datu city for a probability of exceedance in 50 years. The contributions from distant sources, at more than $400 \mathrm{~km}$ are relatively low.

\section{References}

1. Y. Alexander, S. Suratman, A.Liau, M. Hamzah, M. Y. Ramli, H. Ariffin, M. Abd. Manap, M. B. Mat Taib, A. Ali, H. D. Tjia. Report on the Geological and Seismotectonic Information of Malaysia. (Ministry of Natural Resources and Environment, 2006)

2. Y. Alexander, A. Liau, M. Hamzah, M. Y. Ramli, M. B. Mat Taib, A. Ali, H. Ariffin, B. Ismail, H. D. Tjia. Report on Assessment of the Seismic Threats to Malaysia from Major Earthquake in the Southeast Asian Region. (Ministry of Natural Resources and Environment, 2008) 
3. C. S Hutchison. Geology of North West Borneo: Sarawak, Brunei and Sabah. (Elsevier, Boston, 2005)

4. C.S. Hutchison. Marine Geology 271, 32-43 (2010)

5. S. Hesse, S. Back, D. Franke. GSA Bulletin 121, 939-953 (2009)

6. A. B. Cullen. Petroleum Geoscience 16, 3-29 (2010)

7. C. H. Leyu, C. F. Chong, E. P. Arnold, S. L Kho, Y. T. Lim, M. Subramaniam, T. C. Ong, C. K. Tan, K. S. Yap, Y. K. Shu, H. L. Goh. Series on Seismology Malaysia. (E. P. Arnold Southeast Asia Association of Seismology and Earthquake Engineering (SEASEE), 1985)

8. J. F. Pacheco, L. R. Sykes. Bulletin of the Seismological Society of America 82, 13061349 (1992)

9. J. K. Gardner, L. Knopoff. Bulletin of the Seismological Society of America 64, 13631367 (1974)

10. N. Abrahamson, W. Silva. Earthquake Spectra 24, 67-97 (2008)

11. Y. Fukushima, O. Köse, T. Yürür, P. Volant, E. Cushing, R. Guillande. Journal of Seismology 6, 379-396 (2002)

12. K. Sadigh, C. Y. Chang, J. A. Egan, F. Makdisi, R. R. Youngs. Seismological Research Letters 68, 180-189 (1997)

13. J. X. Zhao, J. Zhang, A. Asano, Y. Ohno, T. Oouchi, T. Takahashi, H. Ogawa, K. Irikura, H. K. Thio, P. G. Somerville. Bulletin of the Seismological Society of America 96, 898-913 (2006)

14. S. L. Kramer. Geotechnical Earthquake Engineering. (Prentice Hall PTR, 1996)

15. P. Bazzurro, C. Allin Cornell. Bulletin of the Seismological Society of America 89, 501-520 (1999)

16. S. Harmsen, D. Perkins, A. Frankel. Bulletin of the Seismological Society of America, 89, 1-13 (1999) 